\title{
General practitioner knowledge of prohibited substances in sport
}

\author{
Peter Greenway, Mary Greenway
}

\begin{abstract}
Objectives-To assess general practitioner knowledge of banned substances in sport. Methods-Postal questionnaire sent to all general practitioners in West Sussex. Results-Only 55 (35\%) of those who responded (157 in total) were aware that guidelines are to be found in the British National Formulary, and $19(12 \%)$ of respondents believed that medical practitioners are allowed to prescribe anabolic steroids for non-medical reasons.

Conclusions-General practitioner knowledge of which substances are prohibited in sports is poor. There is a lack of awareness of Sports Council guidelines which are to be found in the British National Formulary. Tackling drug abuse in sport requires education of both athletes and doctors. (Br F Sports Med 1997;31:129-131)
\end{abstract}

Keywords: doping; banned drugs; anabolic steroids; general practitioners

Following several amphetamine related deaths Olympic Committee (IOC) established a medical commission with the aim of eradicating drug abuse in sport. ${ }^{1}$ The first classes banned were psychomotor stimulants, sympathomimetic amines, and narcotic analgesics. The list is regularly updated and in 1975 anabolic steroids were included.

The medical commission produced a list of prohibited substances. The majority, but not all, sports governing bodies adhere to these guidelines. A summary of doping classes and methods with examples can be found in the British National Formulary (BNF). This text also includes a drug information telephone hotline.

The main treatment provider for sports and exercise related injuries in the United Kingdom is the general practitioner. ${ }^{2}$ Athletes suffer the same cross section of illnesses as other patients. Therefore the general practitioner should be aware of prohibited medications and routes of administration permissible in sport.

Langley Corne Surgery, Ifield, Crawley, West Sussex RH11 0NF, United Kingdom P Greenway

M Greenway

Correspondence to: Dr P Greenway.

Accepted for publication 26 February 1997

\section{Methods} IOC medical commission guidelines was sent to all general practitioners in West Sussex. A stamped addressed envelope was included. An accompanying letter stated that the aim of the questionnaire was to assess knowledge of prohibited drugs in sport amongst general practitioners. Those requesting the correct of cyclists in the late 1960s the International

Table 1 Responses to the question where can further information be obtained regarding the list of prohibited substances in sport: (a) BNF; (b) MIMS?

\begin{tabular}{llllll}
\hline & \multirow{2}{*}{ Yes } & & No & & Don't know \\
\cline { 2 - 3 } & Number (\%) & & Number (\%) & & Number (\%) \\
\hline BNF & $55^{\star}(35)$ & & $36(23)$ & $66(42)$ \\
MIMS & $6(4)$ & & $58^{\star}(37)$ & $93(59)$
\end{tabular}

^ Correct answer

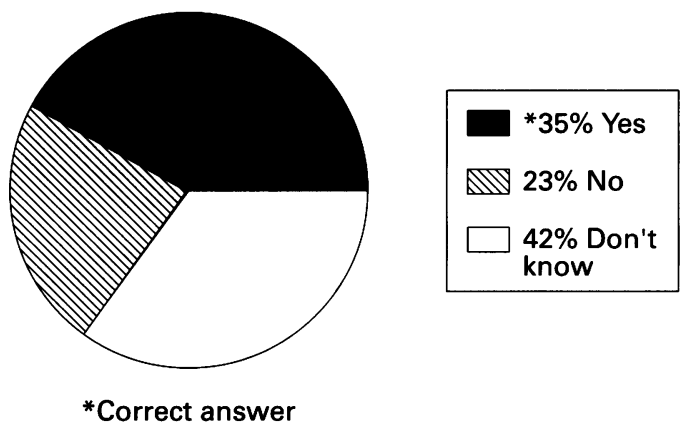

Figure 1 Breakdown of responses to question 1(a).

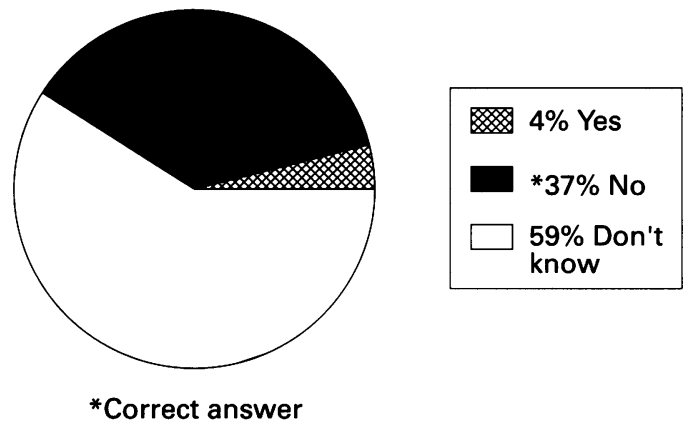

Figure 2 Breakdown of responses to question 1(b).

responses were asked to supply their practice addresses under separate cover.

\section{Results}

From 400 questionnaires sent out, 157 replies were received, which is a response rate of $39.2 \%$.

Question (1) was where can further information be obtained regarding the list of prohibited substances in sport: (a) BNF; (b) Monthly Index of Medical Specialities (MIMS)? Table 1 and figs 1 and 2 give a breakdown of the responses.

Question (2) asked which of the following

A questionnaire to assess cognisance with the drugs are allowed: (a) salbutamol; (b) salmeterol; (c) inhaled corticosteroids; (d) oral corticosteroids; (e) dihydrocodeine; ( $f$ ) dextropropoxyphene (e.g. co-proxamol)? Table 2 and figs 3-8 give a breakdown of the responses.

Question (3) was are doctors allowed to prescribe anabolic steroids for non-medical indications? In all, $111(71 \%)$ correctly answered 
Table 2 Responses to the question which of the following drugs are allowed?

\begin{tabular}{|c|c|c|c|}
\hline & Yes & No & Don't know \\
\hline & Number (\%) & Number (\%) & Number (\%) \\
\hline Inhaled salbutamol & $126^{\star}(80)$ & $11(7)$ & $20(13)$ \\
\hline Inhaled salmeterol & $102 \star(65)$ & 14 (9) & $41(26)$ \\
\hline Inhaled corticosteroids & $102^{\star}(65)$ & 17 (11) & $38(24)$ \\
\hline Oral corticosteroids & 17 (11) & $93 *(59)$ & $47(30)$ \\
\hline Paracetamol & $154^{\star}(98)$ & $1 \quad 0.5)$ & $2(1.5)$ \\
\hline Dihydrocodeine & $23^{\star}(15)$ & $86(55)$ & $48(30)$ \\
\hline Dextropropoxyphene & $9(6)$ & $105^{\star}(67)$ & $43(27)$ \\
\hline
\end{tabular}

$\star$ Correct answer.
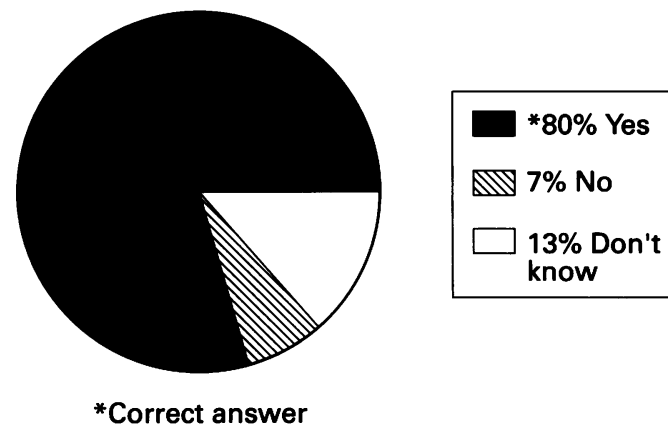

Figure 3 Breakdown of responses to the question is salbutamol allowed.

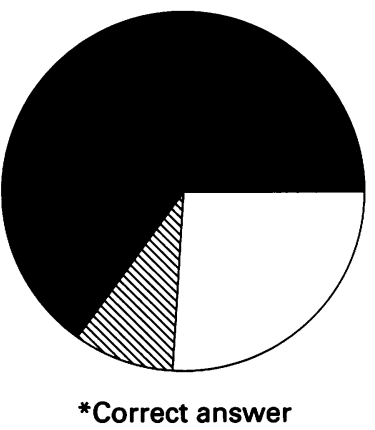

*65\% Yes
9\% No
$\square$ know $26 \%$ Don't
know

Figure 4 Breakdown of responses to the question is salmeterol allowed.

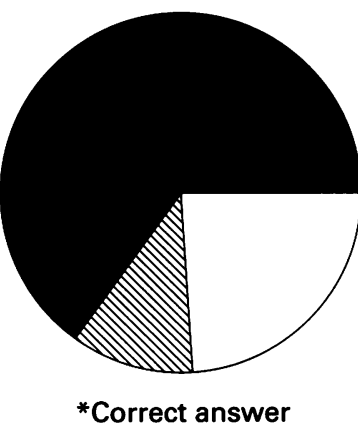

\begin{tabular}{|l|}
\hline$* 65 \%$ Yes \\
$11 \%$ No \\
$\square$ 24\% Don't \\
know
\end{tabular}

Figure 5 Breakdown of responses to the question are inhaled corticosteroids allowed.

no, $19(12 \%)$ thought the answer was yes, and 27 (17\%) did not know (fig 9).

Question (4) asked have you ever prescribed or been asked to prescribe anabolic steroids for performance enhancement or body image purposes? A total of $28(18 \%)$ had been asked but the majority (129) had not (fig 10).

\section{Discussion}

Only one third of respondents were aware that the information on prohibited substances in sport are available in the BNF. Figures 1 and 2 indicate that more research is required to iden-

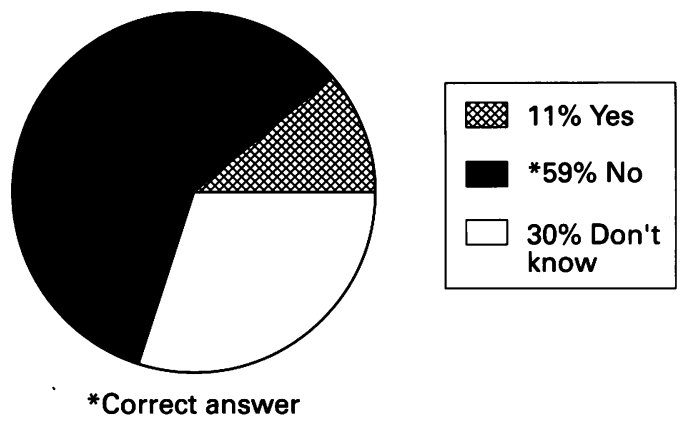

Figure 6 Breakdown of responses to the question are oral steroids allowed.

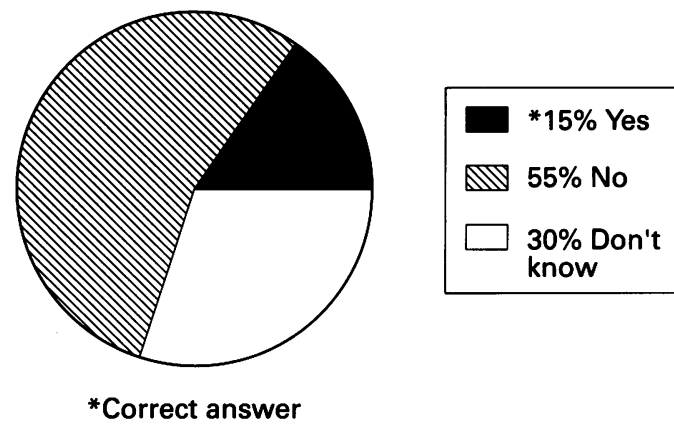

Figure 7 Breakdown of responses to the question is dihydrocodeine allowed.
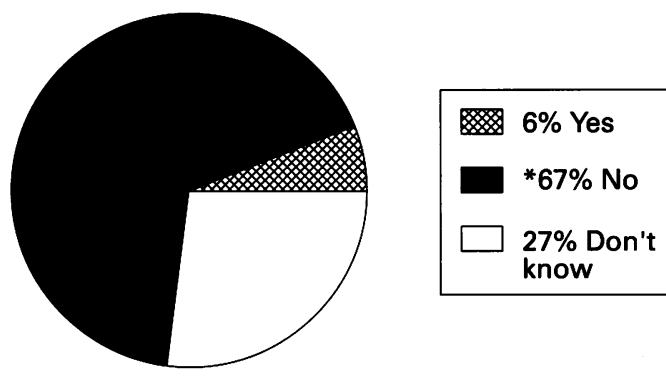

*Correct answer

Figure 8 Breakdown of responses to the question is dextropropoxyphene allowed.

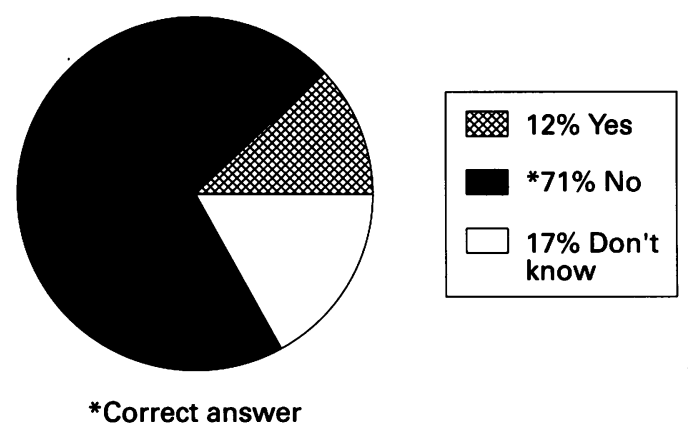

Figure 9 Responses to the question are doctors allowed to prescribe anabolic steroids for non-medical indications.

tify preferred means of general practitioners accessing information (e.g. BNF/MIMS).

In athletes with asthma, ventilation can be a limiting factor to performance, and attacks are often exercise induced. ${ }^{3}$ The only $\beta$ agonists that are allowed are salbutamol, terbutaline, and salmeterol (figs 3 and 4). Corticosteroids have an anti-inflammatory action. Inhalation preparations are allowed in asthma or allergic rhinitis. All oral corticosteroids are banned (see figs 5 and 6). In severe asthmatic attacks, obviously oral prednisolone should not be withheld. 


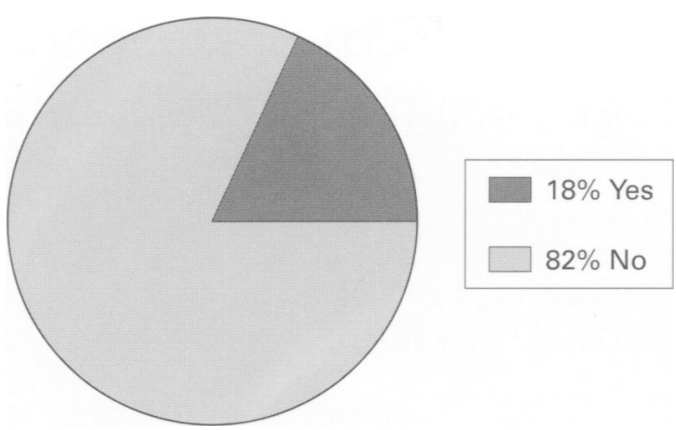

Figure 10 Breakdown of responses to question 4.

Non steroidal anti-inflammatory drugs are allowable orally and topically. They are banned via the intramuscular route but may be used for injection into joints, tendon sheaths, or bursae. There is often a great demand from athletes for injection which they see as a "quick fix" solution to their problems. They should be used appropriately and not to alleviate pain so that the athlete can continue to train and thereby probably aggravate the existing injury. The governing bodies of some competitive sports do not allow injections during or immediately before a sporting competition.

For mild to moderate pain, paracetamol, codeine, and dihydrocodeine are allowed (figs 7 and 8) but not preparations containing opiates such as dextropropoxyphene (coproxamol).

Anabolic steroids remain popular among bodybuilders and power athletes despite numerous warnings about their side effects. Perry et $a l^{4}$ have shown prevalence rates of $35 \%$ in certain gymnasiums. Korkia and Stimson ${ }^{5}$ found that $2 \%$ of athletes in their cohort obtained their supply of anabolic steroids from their general practitioner. Almost one fifth $(18 \%)$ of practitioners had been asked to prescribe anabolic steroids for non-medical reasons (fig 10).

Some $12 \%$ of general practitioners (fig 9) thought that doctors are allowed to prescribe anabolic steroids for non-medical indications. However, there can be no justification for doctors to play any part in the provision of anabolic steroids for use in enhancing athletic performance. $^{6}$
The relatively low response rate may be a reflection of the large levels of paperwork undertaken by general practitioners. Repeat mailings and telephone follow ups for nonresponders may improve this. One practice returned all six of their questionnaires citing lack of time as the reason for non completion. Lack of interest or poor understanding of the subject may have been contributory. Replication of the study in other areas of the country could give useful comparative data. It is encouraging that 39 doctors requested the correct answers. Perhaps individual practices may wish to designate one partner to be the "sports medicine specialist" who may then attend the British Association of Sport and Medicine (BASM) course to enhance their knowledge.

\section{Conclusion}

Control of intentional and non-intentional drug abuse in sport requires the co-operation of both athlete and doctor. Many sportspersons avoid all drug treatment because of concern about failing drugs tests. This is not necessary as in the vast majority of cases satisfactory treatment can be achieved with permitted medications. The list of drugs and other substances banned from sport has evolved over the past few decades and is likely to continue to change. The questionnaire responses suggest that general practitioners need to be better informed of current and updated guidelines. How this is best achieved is yet to be established.

1 Doping and doping control. The Olympic book of sports medicine Vol 1. Oxford: Blackwell Scientific Publications, cine. Vol 1. Ox.

2 Nicholl JP, Coleman P, Williams BT. The epidemiology of sport and exercise related injury in the United Kingdom. Br f Sports Med 1995;4:232-9.

3 Budgett R. Drugs in sport. How to play fair. International Sports Medicine and Soft Tissue Trauma 1996;1:4-6.

4 Perry HM, Wright D, Littlepage BNC. Dying to be big: a review of anabolic steroids. Br F Sports Med 1992;26:259 61 .

5 Korkia P, Stimson GV. Anabolic steroid use in Great Britain. London: The Centre for Research on Drugs and Health Behaviour, 1993.

6 Anstiss TJ. Uses and abuses of drugs in sport: the athletes' view. Medicine, sport and the law. Oxford: Blackwell Scientific Publications, 1987. 